\title{
Detection of Intracytoplasmic Cytokines by Flow Cytometry
}

\author{
Marta A Santiago+, Paula M De Luca, Álvaro L Bertho, Rilza BG Azeredo- \\ Coutinho, Sérgio G Coutinho
}

\author{
Laboratório de Imunidade Celular e Humoral em Protozooses, Departamento de Protozoologia, \\ Instituto Oswaldo Cruz, Av. Brasil 4365, 21045-900 Rio de Janeiro, RJ, Brasil
}

Flow cytometry has been used as a powerful technique for studying cell surface antigen expression as well as intracellular molecules. Its capability of analyzing multiple parameters simultaneously on a single cell has allowed identification and studies of functional cell subsets within heterogeneous populations. In this respect, several techniques have been developed during the past few years to study cytokine-producing cells by flow cytometry in humans and several animal models.

Key words: intracellular cytokines - flow cytometry - leishmaniasis

\section{FLOW CYTOMETRY AND INTRACELLULAR CYTOKINES}

Cytokines are important mediators during immune response and for this reason their role as well as methods for their quantification have been extensively studied in human and animal models. In this context, several strategies for studying cytokine production have been proposed (reviewed in Carter \& Swain 1997). A number of these methodologies are based on the quantification of cytokine-producing cells by flow cytometry (Andersson et al. 1988, Kreft et al. 1992, Jung et al. 1993, Prussin \& Metcalfe 1995, Jason \& Larned 1997).

The flow cytometric method for intracellular cytokine quantification provides: (i) rapid acquisition of great number of cells. This is important because even after in vitro stimulation, the frequencies of cytokine producing cells are very low; (ii) not only determination of the percentage of positive cells but also identifies the subpopulation responsible for cytokine production by simultaneous immunophenotyping and intracellular cytokine staining. By these means, it is possible to study the key role of cytokines and $\mathrm{T}$ cell subpopulations in the immune response to different pathogens. Furthermore, this technique permits the identification of Th 1 , Th 2 and Th 0 cells by simultaneous staining with different anti-cytokine monoclonal antibodies (Elson et al. 1995); (iii) measurement of proteins in the cytoplasm of the cells. Data obtained using polymerase chain reaction (PCR) and ELISA which, respectively, measure the mRNA content

${ }^{+}$Corresponding author. Fax: $+55-21-280.1589$. E-mail: santiago@gene.dbbm.fiocruz.br

Received 9 August 1999

Accepted 23 February 2000 and the cytokine levels in the supernatants of culture do not represent the actual quantities of these proteins because of discordance between the mRNA and the secreted cytokine levels. In addition, cytokine levels in supernatants could be altered by cell consumption of these cytokines in the culture. Moreover it has previously been reported that depending on the cytokine studied there is no correlation between the mRNA levels, the number of spot-forming cells and the cytokine levels in supernatants (Favre et al. 1997). Thus, the intracellular cytokine staining technique should be viewed as a useful methodology to evaluate the cytokine-producing cell in several models. It has been proposed that this technique in association with others, such as proliferative responses, apoptosis and cellular cycle (Mehta \& Maino 1997), could be invaluable for the identification of possible mechanisms involved in the regulation of immune response (Carter \& Swain 1997).

In this connection, several works have been performed using intracellular cytokine staining by flow cytometry to study the possible role of specific cytokines in several diseases including infectious mononucleosis (Andersson \& Andersson 1993), common variable immunodeficiency (North et al. 1996), hyper-IgE-syndrome (Jung et al. 1995) and HIV infection (Meyaard et al. 1996). However few studies have been done using this technique with parasitic diseases as leishmaniasis.

\section{CYTOKINES IN HUMAN LEISHMANIASIS}

Studies on human leishmaniasis caused by Leishmania braziliensis (Lb) (Da-Cruz et al. 1994, Coutinho et al. 1996) suggest that $\mathrm{CD}^{+} \mathrm{T}$ cells and a typical type 1 response (IFN- $\gamma$ ) are associated with the mechanisms of cure in localized cutaneous leishmaniasis (LCL) while the presence of a mixed type 1 (IFN- $\gamma$ ) and type 2 (IL-4) cytokine profiles is associated with active disease. However, 
it has not been possible to determine which $\mathrm{T}$ cell subpopulation is responsible for this shift in the cytokine profile.

Hence, we adapted a flow cytometric technique to evaluate intracytoplasmic cytokines produced by peripheral blood mononuclear cells (PBMC) from American tegumentary leishmaniasis (ATL) patients after in vitro stimulation with $\mathrm{Lb}$ antigens $(\mathrm{LbAg})$. Briefly, cells were fixed with $4 \%$ paraformaldehyde, treated with saponin and stained with FITC-conjugated monoclonal antibodies anti-IL-2, anti-IL-4 and anti-IFN- $\gamma$ respectively. Kinetic studies to identify the best time point at which to detect cytokine-producing cells in ConA-stimulated PBMC from healthy donors showed that the highest levels of IL-2, IL-4 and IFN- $\gamma$ productions were observed at $24 \mathrm{~h}$ after mitogen stimulation. On the other hand, the kinetic studies in ATL patients PBMC showed that the best time point to detect intracellular cytokines was at 16 $\mathrm{h}$ of culture irrespective to the stimulus used (ConA or $\mathrm{LbAg}$ ). Subsequent analysis of intracellular cytokines in cells obtained from patients with different forms of ATL showed that in LCL and in one case of mucocutaneous leishmaniasis there was a mixed type 1 and type 2 cytokine response with the presence of IFN- $\gamma$ and IL- 4 producing cells. In contrast, a typical type 2 cytokine response was found by the cells from one patient with disseminated cutaneous leishmaniasis. These data suggest an important role of cytokine patterns in the immunoregulation of human leishmaniasis (Santiago et al. unpublished data). However, additional studies will be necessary in order to evaluate the role of cytokine produced before and after cure in the different clinical forms of ATL.

\section{CONCLUSIONS}

Currently, two major studies are under investigation in our laboratory concerning cytokine measurement by flow cytometry: the first concerns the use of simultaneous surface phenotype and intracellular cytokine staining and the second involves the use of inhibitory substances, which are able to block protein secretion into the culture supernatants, and as such can be used in an attempt to amplify the fluorescence signals. The available literature points to the fact that the use of these inhibitors in association with paraformaldehyde fixation and saponin permeabilization can be used as an standard assay for studying cytokine production (Schauer et al. 1996).

In conclusion, the technique for detection of intracellular cytokine by flow cytometry seems to be a powerful method to study cytokine production at a single cell level and may help to improve our understanding of the immune response that occur in leishmaniasis as well as in several other diseases.

\section{REFERENCES}

Andersson J, Andersson U 1993. Characterization of cytokine production in infectious mononucleosis studied at a single-cell level in tonsil and peripheral blood. Clin Exp Immunol 92: 7-13.

Andersson U, Halldén G, Persson U, Hed J, Möller G, DeLey M 1988. Enumeration of IFN- $\gamma$-producing cells by flow cytometry. Comparison with fluorescence microscopy. J Immunol Methods 112: 139-142.

Carter LL, Swain SL 1997. Single cell analyses of cytokine production. Curr Opin Immunol 9: 177-182.

Coutinho SG, Oliveira MP, Da-Cruz AM, De Luca PM, Mendonça SCF, Bertho AL, McMahon-Pratt D 1996. T-Cell responsiveness of American cutaneous leishmaniasis patients to purified Leishmania pifanoi amastigote antigens and Leishmania braziliensis antigens: immunologic patterns associated with cure. Exp Parasitol 84: 144-155.

Da-Cruz AM, Conceição-Silva F, Bertho AL, Coutinho SG 1994. Leishmania-reactive CD4+ and CD8 ${ }^{+} \mathrm{T}$ cells associated with cure of human cutaneous leishmaniasis. Infect Immun 62: 2614-2618.

Elson LH, Nutman TB, Metcalfe DD, Prussin C 1995. Flow cytometric analysis for cytokine production identifies T helper 1, T helper 2, and T helper 0 cells within the human $\mathrm{CD} 4^{+} \mathrm{CD} 27^{-}$lymphocyte subpopulation. J Immunol 154: 4294-4301.

FavreN, Bordmann G, Rudin W 1997. Comparison of cytokine measurements using ELISA, ELISPOT and semiquantitative RT-PCR. J Immunol Methods 204: 57-66.

Jason J, Larned J 1997. Single-cell profiles in normal humans: comparison of flow cytometry reagents and stimulation protocols. J Immunol Methods 207: 13-22.

Jung T, Schauer U, Heusser C, Neumann C, Rieger C 1993. Detection of intracellular cytokines by flow cytometry. J Immunol Methods 159: 197-207.

Jung T, Schauer U, Rieger C, Wagner K, Einsle K, Neumann C, Heusser C 1995. Interleukin-4 and interleukin- 5 are rarely co-expressed by human $\mathrm{T}$ cells. Eur J Immunol 25: 2413-2416.

Kreft B, Singer GG, Diaz-Gallo C, Rubin Kelley V 1992. Detection of intracellular interleukin-10 by flow cytometry. J Immunol Methods 156: 125-128.

Mehta BA, Maino VC 1997. Simultaneous detection of DNA synthesis and cytokine production in staphylococcal enterotoxin B activated CD4 ${ }^{+} \mathrm{T}$ lymphocytes by flow cytometry. J Immunol Methods 208: 49-59.

Meyaard L, Hovenkamp E, Keet IPM, Hooibrink B, de Jong IH, Otto AS, Miedema F 1996. Single-cell analysis of IL-4 and IFN- $\gamma$ production by T cells from HIVinfected individuals. J Immunol 157: 2712-2718.

North ME, Ivory K, Funauchi M, Webster ADB, Lane AC, Farrant J 1996. Intracellular cytokine production by human $\mathrm{CD}^{+}$and $\mathrm{CD} 8^{+} \mathrm{T}$ cells from normal and immunodeficient donors using directly conjugated anti-cytokine antibodies and three-colour flow cytometry. Clin Exp Immunol 105: 517-522.

Prussin C, Metcalfe DD 1995. Detection of intracytoplasmic cytokine using flow cytometry and directly conjugated anti-cytokine antibodies. J Immunol Methods 188: 117-128.

Schauer U, Jung T, Krug N, Frew A 1996. Measurement of intracellular cytokines. Trends Immunol Today 17: 305-306. 